\title{
Chronic exercise improves repeated restraint stress-induced anxiety and depression through 5HT1A receptor and cAMP signaling in hippocampus
}

\author{
Mun Hee Kim $^{1}$ and Yea Hyun Leem ${ }^{2 *}$ \\ ${ }^{1}$ Exercise Biochemistry Laboratory, Korea National Sport University, Seoul, Korea \\ ${ }^{2}$ Department of Pharmacy, College of Pharmacy, Dankook University, Cheonan-si, Korea
}

(Received: 2014/01/31, Revised: 2014/02/05, Published online: 2014/02/26)

[Purpose] Mood disorders such as anxiety and depression are prevalent psychiatric illness, but the role of 5HT1A in the anti-depressive effects of exercise has been rarely known yet. We investigated whether long-term exercise affected a depressive-like behavior and a hippocampal 5HT1A receptor-mediated cAMP/PKA/CREB signaling in depression mice model. [Methods] To induce depressive behaviors, mice were subjected to 14 consecutive days of restraint stress ( 2 hours/day). Depression-like behaviors were measured by forced swimming test (TST), and anxiety-like behavior was assessed by elevated plus maze (EPM). Treadmill exercise was performed with $19 \mathrm{~m} / \mathrm{min}$ for $60 \mathrm{~min} /$ day, 5 days/week from weeks 0 to 8 . Restraint stress was started at week 6 week and ended at week 8. To elucidate the role of 5HT1A in depression, the immunoreactivities of 5HT1A were detected in hippocampus using immunohistochemical technique. [Results] Chronic/repeated restraint stress induced behavioral anxiety and depression, such as reduced time and entries in open arms in EPM and enhanced immobility time in FST. These anxiety and depressive behaviors were ameliorated by chronic exercise. Also, these behavioral changes were concurrent with the deficit of 5HT1A and cAMP/PKA/CREB cascade in hippocampus, which was coped with chronic exercise. [Conclusion] These results suggest that chronic exercise may improve the disturbance of hippocampal 5HT1A-regulated cAMP/PKA/CREB signaling in a depressed brain, thereby exerting an antidepressive action. [Keyword] depression; restraint, chronic exercise; 5HT1A, cAMP

\section{INTRODUCTION}

Depression is a heterogeneous mood-related disorder and is known to be implicated in neurotransmitter and neurohormonal pathways, although the mechanism underlying the pathogenesis of depression has been poorly understood yet. Recently, the development of animal models offers an insight into a cue to find the mechanism involved in onset and development of depressive disorder.

Chronic stress is a risk factor for mood- and psychiatryrelated disorders, such as depression and anxiety [1-2]. Aberrant adaptive responses to stress causes the dysregulation of hypothalamic-pituitary-adrenal (HPA) axis and the persistent hyperactivity of mesolimbic reward pathway, thereby leading to psychosomatic illnesses such as depression [3-5].

Serotonin (5-hydroxytryptamine; 5HT) as one of various monoamine neurotransmitters participates in the pathogenesis of anxiety and depression through its receptors [8-10]. Of 14
5HT receptor subtypes, 5HT1A receptor is affiliated to the superfamily of G-protein coupled receptors (GPCRs), which is negatively coupled to the cyclic adenosine-3',5'-monophosphate (cAMP) production [11-12]. The postsynaptic 5HT1A receptor exits at high density in the mesiotemporal cortex, including hippocampus, orbitofrontal cortex and anterior cingulate cortex, while the presynaptic receptor (autoreceptor) is mainly present in dorsal and medial raphe nuclei [9,13-14]. Several studies revealed the hippocampal deficit of 5HT1A receptor in depressed patients and suicidal subjects [9,15-16] and in chronic stress-induced psychiatric disorder animal models [17-19]. More recently, hippocampal glucocorticoid receptor (GR), brain-derived neurotrophic factor (BDNF) and 5HT1A mRNA were significantly reduced, simultaneously with depression-like behavior in early life stress-experienced rats by prolonged maternal separation [10]. Furthermore, most antidepressants such as fluoxentine augment synaptic serotonin tone by inhibiting 5HT reuptake. Long-term antidepressants

\footnotetext{
* Corresponding author: Yea-Hyun Leem, Tel. 82-41-529-6290, Email. leemyy@empas.com

(c)2014 The Korean Society for Exercise Nutrition
} 
treatment enhanced the postsynaptic 5HT1A receptor-modulated transmission in hippocampus [20]. As mentioned above, the role of 5HT1A receptor in the hippocampal serotonin-mediated neural adaptation is considered to be closely linked to depressive behavior and antidepressant response.

Physical activity such as exercise has been well-established to exert an antidepressive action and to have a beneficial effect on emotional health [21-22]. Some studies reported that brain serotonin levels were enhanced by exercise [23-25]. Recently, a study reported that hippocampal 5HT1A receptor mRNA levels of rats subjected to maternal separation were reduced, which was reversed by long-term wheel running treatment, suggesting that the reduced 5HT1A receptor levels of hippocampus in a depressed brain might increase by chronic exercise [10]. Although 5HT1A receptor is a well-known target for serotonin-mediated neuronal response, the relationship between chronic exercise and 5HT1A receptor-mediated neuronal adaptation remains to be elucidated.

Accordingly, we investigated whether long-term exercise could ameliorate a depressive phenotype through a hippocampal 5HT1A receptor-mediated cAMP cascade in stressrelated insulted mice models for depression.

\section{METHODS}

\section{Experimental mice}

Seven weeks old male C57BL/6J mice were obtained from Daehan Biolink, Inc. (Eumsung, Chungbuk, Korea) and housed in clear plastic cages under specified pathogen-free conditions and light-dark cycles of 12/12 hours (lights on at 0600 and off at 1800). All mice had free access to standard irradiated chow (Purina Mills, Seoul, Korea). All animal procedures were approved by the Animal Care and Use Committee of Dankook University, (Cheonan-si, Korea).

\section{Experimental design}

The mice were divided into 3 groups (control: CON, restraint stress: RST, exercise combined with restraint stress group: RST+ Ex; 10-12 mice per group). We employed our previously described exercise protocol [26]. Briefly, treadmill exercise (Myung Jin Instruments Co., Seoul, Korea) was performed with $19 \mathrm{~m} / \mathrm{min}$ for $60 \mathrm{~min} /$ day, 5 days/week from week 0 to week 8 . Treadmill running was administrated at set times at 1800 . To induce restraint stress, 8 -week-old mice were individually placed into a well-ventilated $50-\mathrm{mL}$ conical tube that prevented forward or backward movement. Restraint

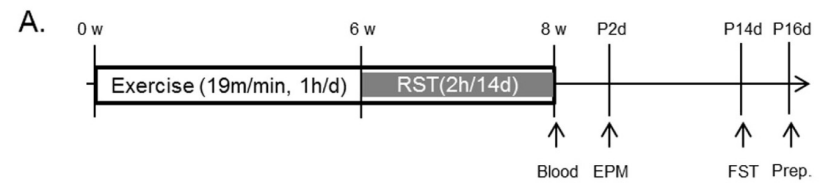

B.

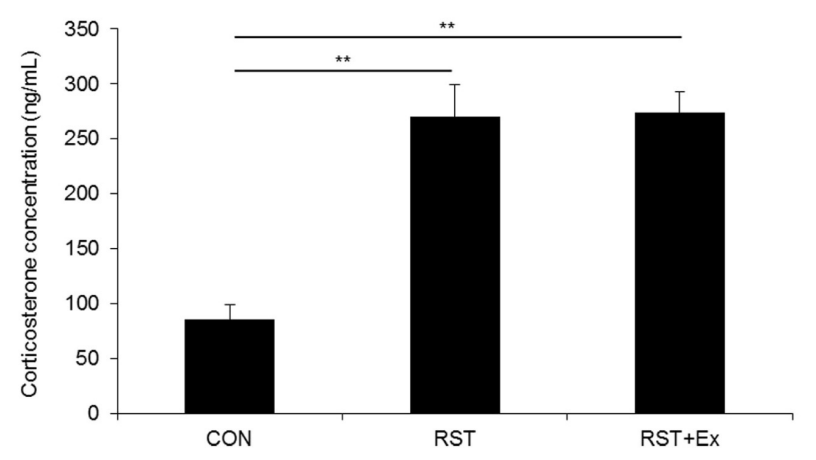

Fig. 1. Experimental design and serum corticosterone levels. (A) Experimental design. (B) Quantitative analysis of serum corticosterone levels.

stress was delivered at set times from 1000 to 1200 for 2 hours. Control mice remained undisturbed in their home cages. This was repeated for 14 days unless otherwise indicated. Mice were subjected to restraint stress from 1000 to 1200 for 2 hours, followed by exercise intervention 6 hours later. Restraint stress was started at week 6 and ended at week 8 week (Fig. 1A).

\section{Behavioral assessment}

To measure the degree of anxiety-like behavior, elevated plus maze (EPM) was conducted using an apparatus consisting of four arms $(30 \times 7 \mathrm{~cm}$ each) produced with black Plexiglas. The apparatus was elevated $50 \mathrm{~cm}$ above the bottom. Two of the arms had $20 \mathrm{~cm}$ high walls (enclosed arms) and the others had no walls (open arms). The mice were initially placed at the center of the platform and left to challenge the arms for 5 minutes. The number of entries and the time spent in open arms were scored.

To measure the despair value by a forced swim test (FST), mice were individually placed in an acryl cylinder $((\Phi) 100$ x (h) $250 \mathrm{~mm}$ ) containing water $\left(23 \pm 1{ }^{\circ} \mathrm{C}\right)$ with a depth of $15 \mathrm{~cm}$ from the bottom. All mice were exposed to the pre-test on day 1 for 15 minutes. After 24 hours were the mice forced to swim and the immobility time was measured without swimming and climbing time via video recording for 6 minutes. The measurement started after the removal of the first minute. KH: Please check if the content is still the same.

Corticosterone measurements 
Blood was collected from the vena hypogastrica after anesthetization with pentobarbital $(40 \mathrm{mg} / \mathrm{kg})$. Blood samples were centrifuged at $1000 \times \mathrm{g}$ for 15 minutes to obtain serum. Corticosterone levels of serum were measured using enzyme immunoassay kits (Cayman Chemical, Ann Arbor, MI, USA).

\section{cAMP measurements}

Hippocampal cyclic AMP contents were evaluated using Elite $^{\mathrm{TM}}$ cAMP ELISA Assay Kit (eEnzyme, Montgomery Village, MD, USA). Extracted supernatants in each sample were loaded into Elite ${ }^{\mathrm{TM}}$ cAMP ELISA Assay Kit plates and each procedure was performed according to the manufacturer's instructions. After color development, absorbance was measured at $\mathrm{Ex} / \mathrm{Em}=540 / 590 \mathrm{~nm}$ with fluorescence reader (Bio-Rad, CA, USA).

\section{Western blot analysis}

Protein samples $(50 \mu \mathrm{g})$ were electrophoretically separated on $10 \%$ polyacrylamide gels, transferred to nitrocellulose membranes (Amersham Bioscience, Buckinghamshire, UK), and incubated with primary antibody in a blocking buffer at room temperature overnight. At the next day, they were washed in a washing buffer and incubated with horseradish peroxidase-conjugated secondary antibody for 2 hours at room temperature. The optical density of each band was measured using SCION program (NIH Image Engineering, Bethesda, MD, USA).

Anti-phospho-cAMP response element-binding protein (CREB), anti-phospho-PKAa, and anti-a-tubulin antibodies were obtained from Cell Signaling Tech. Inc. (Danvers, MA, USA).

\section{Immunohistochemistry}

Mice were perfused through the left cardiac ventricle with $100 \mathrm{mM}$ phosphate buffer ( $\mathrm{pH} 7.4$ ), followed by $40 \mathrm{~mL}$ of cold $4 \%$ paraformaldehyde in $100 \mathrm{mM}$ phosphate buffer. After perfusion, the brains were quickly removed, fixed for 18 hours with the same fixative at $4{ }^{\circ} \mathrm{C}$, and subsequently transferred to 10,20 and $30 \%$ sucrose solutions. Finally, $30 \mu \mathrm{m}$-thick sections were prepared using a vibratome (Leica, Wetzlar, Germany). Free-floating sections were treated with $0.3 \%$ hydrogen peroxide $\left(\mathrm{H}_{2} \mathrm{O}_{2}\right)$ in $100 \mathrm{mM}$ phosphate-buffered saline (PBS) containing $0.3 \%$ Triton X-100 for 30 minutes and nonspecific protein binding was blocked by incubation with 3\% normal goat serum in PBS for 1 hour. Sections were incubated with anti-5HT1A primary antibodies (Abcam,
Cambridge, MA, USA) at $4{ }^{\circ} \mathrm{C}$ overnight. Primary antibodies were reacted with biotinylated secondary antibodies diluted 1:250 in PBS blocking buffer and visualized by the $\mathrm{ABC}$ method (ABC Elite kit, Vector Laboratories; Burlingame, CA, USA) and the sections were mounted. The stained cells were assessed with photo images $($ at $\times 100)$ using Image $J$ program (NIH Image Engineering, Bethesda, MD).

\section{Statistical analysis}

Significant differences among the groups were determined using the one-way analysis of variance (SPSS for Windows, version 18.0, Chicago, IL, USA). Post-hoc comparisons were made using Student-Newman-Keuls tests. All values are reported as mean \pm standard deviation. Statistical significance was set at $\mathrm{p}<0.05$.

\section{RESULTS}

Serum corticosterone levels were markedly enhanced regardless of exercise by restraint stress exposure.

To investigate whether chronic exercise ameliorates depressive phenotype during 14 consecutive days of restraint stress, mice were subjected to treadmill running for 8 weeks. Anxiety levels were measured by EPM 2 days after the last restraint stress and depressive values were determined 14 days after the last restraint stress using FST (Fig. 1A).

To elucidate the role of serum corticosterone in the regulation of mood-related behaviors, serum corticosterone levels were measured immediately after the last restraint stress.

The hormone contents of restrained mice $(269.80 \pm 29.8$ $\mathrm{ng} / \mathrm{mL}$ ) were comparable to that of mice restrained with exercise $(274.1 \pm 18.4 \mathrm{ng} / \mathrm{mL})$, although that of both 2 groups significantly increased relative to that of control $(86.1 \pm 12.7$ $\mathrm{ng} / \mathrm{mL}, \mathrm{p}<0.01$ ) (Fig. 1B).

Chronic exercise mitigated repeated restraint stressinduced anxiety-like and depression-like behavior.

To investigate whether repeated restraint stress provoked anxiety-like and depression-like behavior and whether mice subjected to chronic exercise overcame restraint stressinduced anxiety and depression in our experimental paradigm, we measured anxiety degree and despair value assessed by EPM and FST. As shown in Fig. 2A, the time spent in open arms and the entry into open arms of restrained mice was 
A. a.

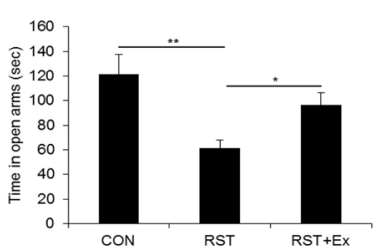

b.

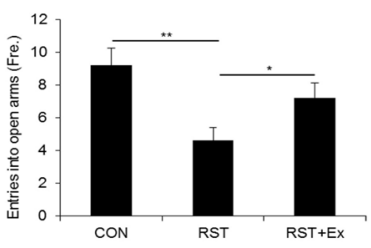

B.

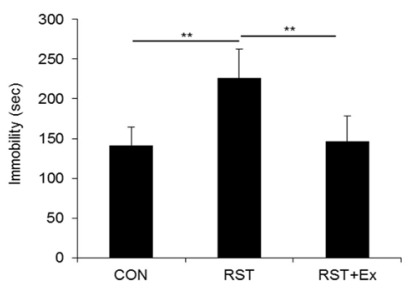

Fig. 2. Chronic exercise mitigated repeated restraint stress-induced anxiety-like and depression-like behavior.(A) Quantitative analysis of time in open arms in EPM. (B) Quantitative analysis of entry in open arms in EPM. (C) Quantitative analysis of immobility time in FST. Data are presented as mean \pm SD $(n=10-12$ animals). $*$ and $* *$ denote differences at $\mathrm{p}<0.05$ and $\mathrm{p}<0.01$, respectively.

\section{A.}

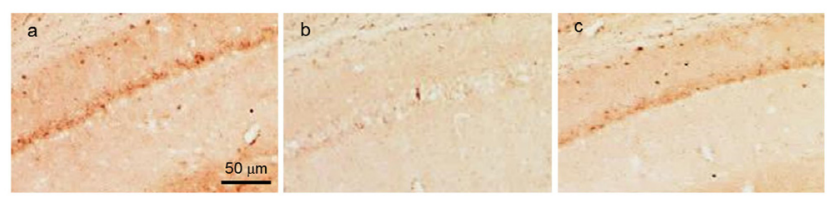

d

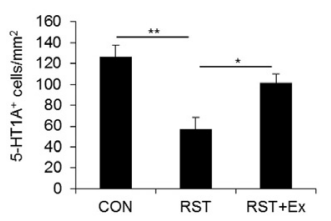

B.
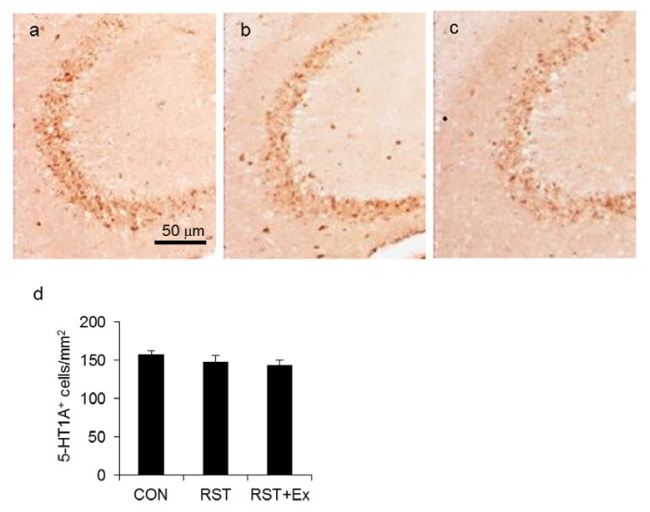

Fig. 3. Chronic exercise coped with repeated restraint stress-induced decrease of hippocampal CA1 5HT1A receptor, but not CA3. (A) Photomicrographs showing CA1 $5 \mathrm{HT} \mathrm{A}^{+}$immunoreactivity (a, Control; b, Restraint; c, Restraint with exercise; d, Quantitative analysis of CA1 5HT1A ${ }^{+}$immunoreactivity). (B) Photomicrographs showing CA3 5HT1A immunoreactivity (a, Control; b, Restraint; c, Restraint with exercise; d, Quantitative analysis CA3 $5 \mathrm{HT} \mathrm{A}^{+}$immunoreactivity). Data are presented as mean $\pm \mathrm{SD}(\mathrm{n}=10-12$ animals). $*$ and $* *$ denote differences at $\mathrm{p}<0.05$ and $\mathrm{p}<0.01$, respectively. significantly reduced compared to that of control mice $(\mathrm{p}<$ $0.01)$, which was reversed by chronic exercise $(\mathrm{p}<0.05)$. Consistently, the immobility time of restrained mice profoundly increased compared to that of control mice $(\mathrm{p}<0.01)$, whereas the enhanced immobility time was conversely reduced by chronic exercise $(\mathrm{p}<0.01)$ (Fig. $2 \mathrm{~B})$.

Chronic exercise coped with repeated restraint stressinduced the decrease of hippocampal CA1 5HT1A receptor, but not CA3.

Given that chronic exercise mitigates a repeated restraint stress-provoked anxious and depressive phenotype, we assessed the hippocampal 5HT1A receptor between groups using immunohistochemical analysis. As shown in Fig. 3A, the immunohistochemistry of anti-5HT1A antibodies revealed that the immunoreactivities of 5HT1A receptor in hippocampal CA1 of restrained mice were notably reduced compared to that of control mice $(p<0.01)$, whereas the reduced immunoreactivities were conversely enhanced by chronic exercise $(p<0.05)$. On the other hand, this change

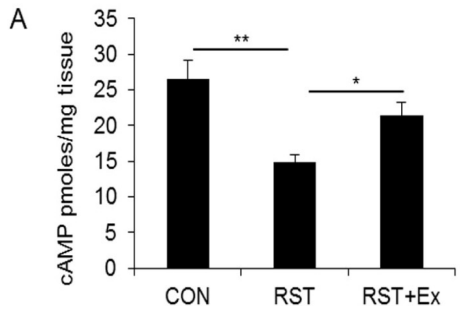

B a CON RST RST+EX

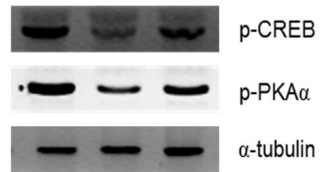

b

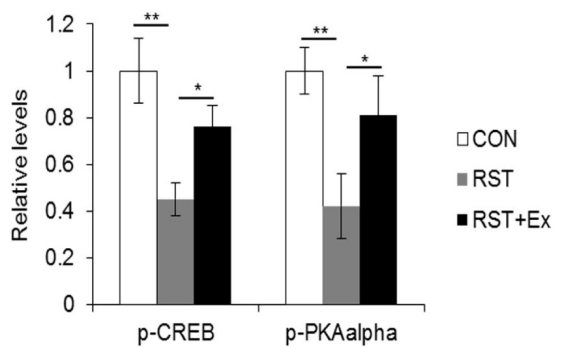

Fig. 4. Chronic exercise restored repeated restraint stress-induced deficit of cAMP/PKA/CREB cascade in hippocampus. (A) Quantitative analysis of hippocampal cAMP contents. (B) Photomicrographs showing phosphoCREB and phospho-PKAa immunoreactivity. (a, Western blotting for phospho-CREB and phospho-PKAa; b, Quantitative analysis of phosphoCREB and phospho-PKAa). Data are presented as mean \pm SD $(n=10-12$ animals). ${ }^{*}$ and $* *$ denote differences at $\mathrm{p}<0.05$ and $\mathrm{p}<0.01$, respectively. 
of 5HT1A receptor was not observed in hippocampal CA3 (Fig. 3B).

Chronic exercise restored the repeated restraint stressinduced deficit of cAMP/PKA/CREB cascade in hippocampus.

To investigate the relationship between 5HT1A receptor and cAMP/PKA/CREB signaling that are involved in the BDNF-mediated antidepressive action in hippocampus, we conducted a fluorometric analysis for cAMP measurement and western blotting with antibodies which recognized phosphoPKAa and phospho-CREB. Hippocampal cAMP contents in restrained mice (14.85 \pm 1.02 pmoles $/ \mathrm{mg}$ tissue) were profoundly reduced compared to that of control mice (26.55 $\pm 2.56 \mathrm{pmoles} / \mathrm{mg}$ tissue $)(\mathrm{p}<0.01)$, which was reversed by chronic exercise $(21.35 \pm 1.84$ pmoles $/ \mathrm{mg}$ tissue $)(\mathrm{p}<0.05)$ (Fig. 4A). Consistently, hippocampal phospho-PKA and phospho-CREB levels in depressed brains significantly decreased $(p<0.01)$, whereas reduced in those that were conversely augmented by chronic exercise $(p<0.05)$ (Fig. 4B).

\section{DISCUSSION}

The present study delineated that the 14 consecutive days of restraint stress produced anxiety-like and depression-like behaviors and the deficit of hippocampal CA1 5HT1A receptor, concomitant with the disturbance of cAMP/PKA/ CREB signaling. These behavioral and cellular episodes were overcome by chronic exercise.

Chronic stress is known to be implicated in the pathogenesis of psychiatric disorders, such as depression and anxiety [1-2]. In depression animal models, chronic restraint stress insult was an appropriate paradigm for psychiatric-related illnesses in rodents because of the effective induction of anxiety and depressive phenotype, which were reversed by antidepressant treatment [6-7]. The previous studies were consistent with this notion, namely that our repeated restraint stress paradigm $(2 \mathrm{~h} / 14 \mathrm{~d})$ was a valid mice model for depression.

First, to prove anxiolytic and antidepressive effects of exercise, we verified whether chronic exercise coped with repeated restraint stress-induced psychiatric insults such as anxiety and depression in our experimental paradigm. Chronic exercise alleviated restraint stress-produced anxiety-like and depression-like behavior respectively measured by EPM and FST. The previously documented studies about the beneficial effects of exercise on mood- and psychosomatic-related disorders support our result that chronic exercise exerts an anxiolytic and antidepressive effect on repeated restraint stress-induced anxiety and depressive phenotypes [21-22].

These behavioral changes were coincided with that in hippocampal CA1 5HT1A receptors in our experimental paradigm. The role of $5 \mathrm{HT}$ receptors in regulating anxiety and depression is well-established [8,27-28]. Especially, $5 \mathrm{HT} 1 \mathrm{~A}$ receptor has been considered as an attractive target for anxiolytic and antidepressive strategies due to a wellknown serotonin response. 5HT1A receptor is one of the 5HT receptor subtypes and is negatively coupled to adenylyl cyclase. The somatodendritic 5HT1A autoreceptor is located on the serotonergic neuron in dorsal and medial raphe nuclei, which activation results in the decline of the firing rate of 5HT neurons and the blockage of 5HT synthesis and releases into projection regions [14,29-30]. Postsynaptic 5HT1A is present in limbic structures such as hippocampus, which activation decreases the firing rate of postsynaptic cells $[9,13$, 31]. Several studies reported that an antidepressant treatment produced tonic activation of postsynaptic 5HT1A receptors and 5HT1A knockout mice which typically produced behavioral anxiety have been a useful model for anxiety-related disorders $[14,20,32]$. Also, a reduced postsynaptic 5HT1A receptor in the hippocampus was revealed in depressed subjects and depression animal models [9-10,15-19]. Studies reported above were in line with our result that a repeated restraint stress induced the deficit of postsynaptic 5HT1A receptors in hippocampus along with behavioral anxiety and depression. A positive correlation between the deficit of postsynaptic 5HT1A and a depressive phenotype is probably attributed to a repeated restraint stress-induced presynaptic 5HT1A receptor activation and postsynaptic plasticity alteration. The former may be explained thereby that repeated restraint stress activates somatodendritic 5HT1A autoreceptors and then reduces the firing rate of 5HT neurons and the release into the projection region such as hippocampus, thereby decreasing 5HT tonic and extracellular serotonin concentration in hippocampus. In the latter, the repeated restraint stress may induce a persistent corticosterone elevationmodulated reduction of synaptic plasticity. On the other hand, chronic exercise is likely to induce 5HT-mediated desensitization of 5HT1A autoreceptor, thereby causing a recovery of the firing rate of 5HT neuron in raphe nuclei that increase the postsynaptic tone and extracellular contents of 5HT in the projection area such as in hippocampus. This possible mechanism of antidepressive effects of chronic exercise is supported by previously published articles. Serotoninenhancing antidepressants augment synaptic serotonin tone by presynaptic 5HT1A autoreceptor desensitization of 5HT neuron in raphe nuclei through inhibiting 5HT reuptake [33-34]. A long-term treatment with antidepressants enhanced 
the postsynaptic 5HT1A receptor-modulated transmission in hippocampus [20]. Also, physical activity such as exercise is known to enhance brain serotonin levels [23-24].

We examined if chronic exercise elevated hippocampal 5HT tone via 5 HT1A receptor desensitization. Thus, we investigated the change of 5HT-regulated cAMP/PKA/CREB cascade in the hippocampus. cAMP/PKA/CREB cascade is well-known to be regulated by serotonin and norepinephrine, and chronic antidepressant treatment up-regulates cAMP signal transduction and PKA activity in brain [35-36]. Several studies demonstrated that hippocampal CREB-dependent BDNF expression was deeply linked to chronic stress and psychiatric disorders including depression [37-38]. Our western blotting data revealed that reduced cAMP contents, phospho-PKA and phospho-CREB levels in the hippocampus of a depressed brain were conversely enhanced by chronic exercise. We previously reported that the 21 consecutive days of restraint stress reduced hippocampal phospho-CREB and BDNF levels and were restored by chronic exercise [39]. Other results reported that hippocampal BDNF and 5HT1A mRNA levels decreased by prolonged maternal separation, which was reversed, concurrent with an antidepressive behavior by exercise [10]. Also, an exercise-induced hippocampal brain-derived neurotrophic factor (BDNF) elevation was proved to be CREB-dependent using CREB repressor mutant mice [40]. These results support at least in part our result that chronic exercise improves hippocampal cAMP/PKA/CREB signaling.

Taken together, a repeated restraint stress caused the deficit of 5HT1A receptor and 5HT-mediated cAMP/PKA/CREB cascade in hippocampus, thereby producing behavioral anxiety and depression. These behavioral and cellular episodes were reversed by chronic exercise. Accordingly, our findings may provide a better understanding about the role of hippocampal 5HT1A receptor-regulated cAMP signaling in a depressive phenotype and the antidepressive effects of chronic exercise.

\section{CONCLUSION}

The current study demonstrated that chronic exercise ameliorated repeated restraint stress-provoked anxiety and depression-like behaviors through the restored 5HT1A receptormediated cAMP/PKA/CREB signal transduction in the hippocampal CA1 sub-region. Our results suggest that the antidepressive effects of chronic exercise may be attributed at least in part to the hippocampal 5HT1A receptor-modulated cAMP signal cascade.

\section{ACKNOWLEDGEMENTS}

The current study was supported by the National Research Foundation of Korea Grant funded by the Korean Government [NRF-2013R1A1A2062984].

\section{REFERENCES}

[1] Ader R and Cohen N. (1993) Psyconeuroimmunology: conditioning and stress. Annu Rev Psychol. 1993;44, 53-85.

[2] van Praag HM. Can stress cause depression? Prog NeuroPsychopharmacol Biol Psychiat. 2004;28,891-907.

[3] Berton O, McClung CA, DiLeone RJ, Krishnan V, Renthal W, Russo SJ, Graham D, Tsankova NM, Bolanos CA, Rios M, Monteggia LM, Self DW, Nestler EJ. Essential Role of BDNF in the Mesolimbic Dopamine Pathway in Social Defeat Stress. Science 2006;311: 864-868.

[4] Cryan JF and Holmes A. The ascent of mouse: advances in modeling human depression and anxiety. Nat Rev Drug Discov 2005;4:775-790.

[5] Duman, C. H., Schlesinger, L., Kodama, M., Russell, D. S., Duman, R. S. A role for MAP kinase signaling in behavioral models of depression and antidepressant treatment. Biol. Psychiatry 2007;61:661-670.

[6] Seo JS, Park JY, Kim TK, Shin JH, Lee JK, Han PL. NADPH oxidase mediates depressive behavior induced by chronic stress in mice. J Neurosci. 2012;32:96909699.

[7] Christiansen SH, Olesen MV, wortwein G, Woldbye DP. Fluoxentine reverts chronic restraint stress-induced depression-like behavior and increases neuropeptide $\mathrm{Y}$ and galanin expression in mice. Behav Brain Res. 2011; 216:585-591.

[8] Cryan JF, Leonard BE. 5-HT1A and beyond: the role of serotonin and its receptors in depression and the antidepressant response. Hum Psychopharmacol. 2000;15:113135.

[9] Moses-Kolko EL, Wisner KL, Price JC, Berga SL, Drevets WC, Hanusa BH, Loucks TL, Meltzer CC. Serotonin 1A receptor reductions in postpartum depression: a positron emission tomography study. Fertil Steril. 2008;89:685-92.

[10] Maniam J and Morris M. Voluntary exercise and palatable high-fat diet both improve behavioural profile and stress responses in male rats exposed to early life stress: Role of hippocampus. Psychoneuroendocrinol. 2010;35:1553- 
1564.

[11] Hoyer D and Schoeffter P. 5-HT receptors: subtypes and second messengers. J Recept Res. 1991;11:197-214.

[12] Nash MS and Osborne NN. Pharmacologic evidence for 5-HT1a receptors associated with human retinal pigment epithelial cells in culture. Invest Ophthalmol Vis Sci. 1997;38:510-519.

[13] Pazos A, and Palacios JM. Qunatitative autoradiographic mapping of serotonin receptors in rat brain. Serotonin-1 receptors. Brain Res. 1985;346:205-230.

[14] Toth M. 5-HT1a receptor knockout mouse as a genetic model of anxiety. European J Pharmacol. 2003;463:177184.

[15] Cheetham SC, Crompton MR, Katona CL, Horton RW. Brain 5-HT1 binding sites in depressed suicides. Psychopharmacol (Berlin) 1990;102:544-548.

[16] Sargent PA, Kjaer KH, Bench CJ, Rabiner EA, Messa C, Meyer J, Guun RN, Grasby PM, Cowen PJ. Brain serotonin1A receptor binding measured by positron emission tomography with [11c] WAY-100635: effects of depression and antidepressant treatment. Arch Gen Psychiatry 2000;57:174-180.

[17] Watanabe Y, Sakai RR, McEwen BS, Mendelson S. Stress and antidepressant effects on hippocampal and cortical 5-HT1A and 5-HT2 receptors and transport sites for serotonin. Brain Res. 1993;615:87-94.

[18] Lopez RG, Chalmers DT, Little KY, Watson SJ. A.E. Bennett Research Award. Regulation of serotonin1A, glucocorticoid, and mineralocorticoid receptor in rat and human hippocampus: implications for the neurobiology of depression. Biol Psychiatry 1998;43:547-573.

[19] Wissink S, Meijer O, Pearce D, van Der Burg B, van Der Saag PT. Regulation of the rat serotonin-1A receptor gene by corticosteroids. J Biol Chem. 2000;275:13211326.

[20] Haddjeri N, Blier P, de Montigny C. Long-term antidepressant treatments results in a tonic activation of forebrain 5-HT1A receptors. J Neurosci. 1998;10150-6.

[21] Hill, R. D., Storandt, M., Malley, M. The impact of long-term exercise training on psychological function in older adults. J Gerontol. 1993;48:P12-17.

[22] Booth, F. W., Chakravarthy, M. V., Spangenburg, E. E. Exercise and gene expression: Physiological regulation of the human genome through physical activity. J Physiol. 2002;543,399-411.

[23] Duman, R. S. Malberg, J., Thome, J. Neural plasticity to stress and antidepressant treatment. Biol. Psychiatry, 1999;46:1181-1191.

[24] Tang, S. W., Chu, E., Hui, T., Helmeste, D., Law, C.
Influence of exercise on serum brain-derived neurotrophic factor concentrations in healthy human subjects. Neurosci Lett. 2008;431:62-65.

[25] Soares DD, Coimbra CC, Marubayashi U. Tryptophaninduced central fatigue in exercising rats is related to serotonin content in preotic area. Neurosci Lett. 2007; 415:274-278.

[26] Kim BS, Kim MY, Leem YH. Hippocampal neuronal death induced by kainic acid and restraint stress is suppressed by exercise. Neuroscience 2011;194:291-301.

[27] Stockmeier C. Involvement of serotonin in depression: evidence from postmortem and imaging studies of serotonin receptors and the serotonin transporter. J Psychiatry Res. 2003;37:357-373.

[28] Contesse V, Lefebvre H, Lenglet S, Kuhn JM, Delarue $\mathrm{C}$, Vaudry H. Role of 5HT in regulation of the brainpituitary-adrenal axis: effects of 5HT on adrenocortical cells. Can J Physiol Pharmacol. 2000;78:967-983.

[29] Blier P, de Montigny C, Tardif D. Short-term lithium treatment enhances responsiveness of postsynaptic 5-HT1A receptors without altering 5-HT autoreceptor sensitivity: an electrophysiological study in the rat brain. Synapse 1987;1:225-232.

[30] Kennett GA, Marcou M, Dourish CT, Curzon G. Single administration of 5-HT1A agonists decreases 5-HT1A presynaptic, but not postsynaptic receptor-mediated response: relationship to antidepressant-like action. Eur J Pharmacol. 1987;138:53-60.

[31] Sprouse JS and Aghajanian GK. Responses of hippocampal pyramidal cells to putative serotonin 5-HT1A and 5-HT1B agonists: a comparative study with dorsal raphe neurons. Neuropharmacol. 1988;27:707-715.

[32] Freeman-Daniels E, Beck SG, Kirby LG. Cellular correlates of anxiety in CA1 hippocampal pyramidal cells of 5-HT1A receptor knockout mice. Psychopharmacol. 2011;213, 453-463.

[33] Bel N, Artigas F. Chronic treatment with fluvoxami9ne increases extracellular serotonin in frontal cortex but not in raphe nuclei. Synapse 1993;15:243-5.

[34] Blier P, de Montigny C. Current advances and trends in the treatment of depression. Trends Pharmacol Sci 1994; 15:220-6.

[35] Perez J, Tinelli D, Brunello N, Racagni. cAMP-dependent phosphorylation of soluble and crude microtubule fractions of rat cerebral cortex after prolonged desmethylimipramine treatment. Eur J Pharmacol. 1989;172:305-16.

[36] Nestler EJ, Terwilliger RZ, Duman RS. Chronic antidepressant administration alters the subcellular distribution of cyclic AMP-dependent protein kinase in rat frontal 
cortex. J Neurochem. 1989;53:1644-7.

[37] Duman RS, Monteggia LM. A neurotrophic model for stress-related mood disorders, Biol. Psychiatry 2006;59: 1116-1127.

[38] McEwen BS. Glucocorticoids, depression, and mood disorders: structural remodeling in the brain, Metabolism 2005;54:20-23.
[39] Kwon DH, Kim BS, Chang H, Kim YI, Ahn Jo S, Leem YH. Exercise ameliorates cognition impairment due to restraint stress-induced oxidative insult and reduced BDNF level. BBRC, 2013;434:245-251.

[40] Chen MJ, Russo-Neustadt AA. Running exercise-induced up-regulation of hippocampal brain-derived neurotrophic factor is CREB-dependent. Hippocampus, 2009;19:962-972. 